\title{
INVERSE PROBLEMS OF RECOVERING THE BOUNDARY DATA WITH INTEGRAL OVERDETERMINATION CONDITIONS
}

\author{
S.G. Pyatkov, M.A. Verzhbitskii \\ Yugra State University, Khanty-Mansyisk, Russian Federation \\ E-mail: s_pyakov@ugrasu.ru
}

\begin{abstract}
In the present article we examine an inverse problem of recovering unknown functions being part of the Dirichlet boundary condition together solving an initial boundary problem for a parabolic second order equation. Such problems on recovering the boundary data arise in various tasks of mathematical physics: control of heat exchange prosesses and design of thermal protection systems, diagnostics and identification of heat transfer in supersonic heterogeneous flows, identification and modeling of heat transfer in heat-shielding materials and coatings, modeling of properties and heat regimes of reusable heat protection of spacecrafts, study of composite materials, etc. As the overdetrermination conditions we take the integrals of a solution over the spatial domain with weights. The problem is reduced to an operator equation of the Volterra-type. The existence and uniqueness theorem for solutions to this inverse problem is established in Sobolev spaces. A solution is regular, i. e., all generalized derivatives occuring into the equation exists and are summable to some power. The proof relies on the fixed point theorem and bootstrap arguments. Stability estimates for solutions are also given. The solvability conditions are close to necessary conditions.

Keywords: inverse problem; parabolic equation; boundary and initial condition; Sobolev space; existence and uniqueness theorem; solvability.
\end{abstract}

\section{Introduction}

We consider the parabolic equation

$$
L u=u_{t}-\sum_{i, j=1}^{n} \frac{\partial}{\partial x_{i}} a_{i j}(t, x) u_{x_{j}}+\sum_{i=1}^{n} a_{i}(t, x) u_{x_{i}}+a_{0}(t, x) u=f,
$$

where $x \in G \subset \mathbb{R}^{n}$ is a bounded domain with boundary $\Gamma$ of the class $C^{2}$ (see the definition, for instance, in [1, Sect. 1]), $t \in(0, T)$. Put $Q=(0, T) \times G$ and $S=(0, T) \times \Gamma$. The equation (1) is furnished with the following initial and boundary conditions:

$$
\left.u\right|_{S}=g,\left.u\right|_{t=0}=u_{0}(x) \text {. }
$$

Put $\frac{\partial u}{\partial N}=\sum_{i, j=1}^{n} a_{i j}(t, x) u_{x_{j}}(t, x) v_{i}$, where $v=\left(v_{1}, v_{2}, \ldots, v_{n}\right)$ is the outward unit normal to $S$. The inverse problem is to find a solution $u$ to the problem (1)-(2) and a function $g$ of the form $g=\sum_{i=1}^{m} q_{i}(t) \Phi_{i}(t, x)$, where the vector $\vec{q}=\left(q_{1}, q_{2}, \ldots, q_{m}\right)$ is unknown, with the use of the overdetermiantion conditions

$$
\int_{G} u(x, t) \varphi_{k}(x) d x=\psi_{k}(t), k=1,2, \ldots, m .
$$

Inverse problems of recovering boundary regimes, in particular, the convective heat exchange problems are conventional (see, for instance, [2-11]). They arise in different problems of mathematical physics such as the problems of control of heat exchange prosesses and design of thermal protection systems, diagnostics and identification of heat transfer in supersonic heterogeneous flows, identification and modeling of heat transfer in heat-shielding materials and coverings, modeling of properties and heat regimes of reusable heat protection of spacecrafts, the study of composite materials, etc. Mathematical models describing these prosesses and the corresponding inverse problems in both one-dimensional and multidimensional cases are described, for example, in [2]. The essential attention here is paid to numerical methods of solving inverse problems in question and some uniqueness theorems together stability estimates for solutions. We refer also to the monograph [3] mainly devoted to numerical 


\section{Математика}

methods of determining a solution, where in the one-dimensional case different inverse problems for parabolic equations and problems of recovering the boundary regimes as well are studied. The overdetrermination conditions are the values of a solution at some points lying inside the spatial domain. These problems are studied in different settings in dependence on the type of the ovedetermination conditions. It is often the case when these problems are ill-posed in the Hadamard sense. In particular, it is true in the case of the overdetermination conditions in the form of values of a solution at separate points or on some surfaces lying in the spatial domain (see [2]). At the present article we examine the problems with overdetermination conditions in the form of some integrals with weights of a solution over a spatial domain. Note that these conditions arise in applications and they are often used in literature. Inverse problems of recovering the right-hand side or coefficients of an equation with integral ovedetermination conditions are studied in the articles [12-18], the monographs [19, 20], and some other articles. In particular, the existence and uniqueness theorem of a generalized solution to the problem (1)-(3) (from the class $u \in W_{2}^{0,1}(Q)$ ) in the case of $m=1$ and the Neumann boundary condition was obtained in [9] and a similar result for a heat-and-mass transfer system including the Navier-Stokes system and a parabolic equation for the concentration of an admixture was obtained in [10]. The article [11] is devoted to a regular solvability $\left(u \in W_{2}^{1,2}(Q)\right)$ in the case of $m=1$ and the Robin boundary conditions. The case of the Dirichlet boundary condition happens to be more complicated than the case of the Neumann (Robin) boundary conditions and was not studied before. The present article is devoted to this case. Under some conditions on the data we prove well-poseness of this problem. The article in some sense is an extension of [21], where the Robin boundary conditions are treated. Some our auxiliary statements are taken from this article.

\section{Preliminaries}

Let $E$ be a Banach space. Denote by $L_{p}(G ; E)$ ( $G$ is a domain in $\mathbb{R}^{n}$ ) the space of strongly measurable functions defined on $G$ with values in $E$ and the finite norm \|\|$u(x)\left\|_{E}\right\|_{L_{p}(G)}$ [1]. We also employ the Holder spaces (see the definition for instance, in [22]) $C^{\alpha, \beta}(\bar{Q}), C^{\alpha, \beta}(\bar{S}), C^{k}(\bar{G})$ and the Sobolev spaces $W_{p}^{s}(G ; E), W_{p}^{s}(Q ; E)$ (see $\left.[21,23]\right)$. If $E=\mathbb{R}$ or $E=\mathbb{R}^{n}$ then the latter space is denoted by $W_{p}^{s}(Q)$. Given an interval $J=(0, T)$, put $W_{p}^{s, r}(Q)=W_{p}^{s}\left(J ; L_{p}(G)\right) \cap L_{p}\left(J ; W_{p}^{r}(G)\right.$. Respectively, $W_{p}^{s, r}(S)=W_{p}^{s}\left(J ; L_{p}(\Gamma)\right) \cap L_{p}\left(J ; W_{p}^{r}(\Gamma)\right)$. All spaces and the coeffciecients of the equation (1) are assumed to be real. Let $(u, v)=\int_{G} u(x) v(x) d x, Q^{\gamma}=(0, \gamma) \times G$ and $S^{\gamma}=(0, \gamma) \times \Gamma$.

We endow the space $W_{p}^{s}(0, \tau ; E) \quad(s \in(0,1), \quad E$ is a banach space, with the norm $\|q(t)\|_{W_{p}^{s}(0, \tau ; E)}=\left(\|q\|_{L_{p}(0, \tau ; E)}^{p}+\left\langle q>_{s, \tau}^{p}\right)^{1 / p},\left\langle q>_{s, \tau}^{p}=\int_{0}^{\tau} \int_{0}^{\tau} \frac{\left\|q\left(t_{1}\right)-q\left(t_{2}\right)\right\|_{E}^{p}}{\left|t_{1}-t_{2}\right|^{1+s p}} d t_{1} d t_{2}\right.\right.$. If $E=\mathbb{R}$ then we obtain the conventional Sobolev space $W_{p}^{s}(0, \tau)$. For $s \in(1 / p, 1]$, we put $\tilde{W}_{p}^{s}(0, \tau)=\left\{q \in W_{p}^{s}(0, \tau): q(0)=0\right\}$. This class is a Banach space with the norm $\|\cdot\|_{W_{p}^{s}(0, \tau)}$. We can define also the equivalent norm $\|q(t)\|_{\tilde{W}_{p}^{s}(0, \tau)}^{p}=\left\|\frac{q}{t^{s}}\right\|_{L_{p}(0, \tau)}^{p}+\langle q\rangle_{s, \tau}^{p}$. The equivalence results from Lemma 1 of the subsection 3.2.6 [1]. Similarly, we can define the spaces $\tilde{W}_{p}^{s}\left(0, \tau ; L_{p}(G)\right), \tilde{W}_{p}^{s, 2 s}\left(Q^{\tau}\right)$ comprising, the functions $v(t, x)$ in $W_{p}^{s}\left(0, \tau ; L_{p}(G)\right)$ and $W_{p}^{s, 2 s}\left(Q^{\tau}\right)$, respectively, such that $v(0, x)=0$. The new norms $\|\cdot\|_{\tilde{W}_{p}^{s}\left(0, \tau ; L_{p}(G)\right)},\|\cdot\|_{\tilde{W}_{p}^{s, 2 s}\left(Q^{\tau}\right)}$ are defined naturally with the use of the above norm $\tilde{W}_{p}^{s}(0, \tau)$

Lemma 1. Let $s \in(1 / p, 1)$ and $p \in(1, \infty)$. Then the following statements are valid. 
1) Let $q(t) \in W_{p}^{s}(0, \tau) \quad(\tau \in(0, T])$. Then $q \in C([0, \tau])$ after a possible change on a set of zero measure. If $q(0)=0$ and $\tilde{q}$ is an extension by zero of $q$ for $t \leq 0$ then

$$
\|q\|_{W_{p}^{s}(-T+\tau, \tau)} \leq c_{1}\|q\|_{\tilde{W}_{p}^{s}(0, \tau)},
$$

where the constant $c_{1}$ is independent of $\tau \in(0, T]$ and $q$.

2) The product $q \cdot v$ of functions in $W_{p}^{s}(0, \tau) \quad(\tau \in(0, T])$ belongs to $W_{p}^{s}(0, \tau)$ and if $q \in \tilde{W}_{p}^{s}(0, \tau)$ and $v \in W_{p}^{s}(0, \tau)$ then $q v \in \tilde{W}_{p}^{s}(0, \tau)$. Moreover, the following estimate holds:

$$
\|q v\|_{\tilde{W}_{p}^{s}(0, \tau)} \leq c_{2}\|q\|_{\tilde{W}_{p}^{s}(0, \tau)}\left(\langle v\rangle_{s, \tau}+\|v\|_{L_{\infty}(0, \tau)}\right),
$$

where the constant $c_{2}$ is independent of $q, v$, and $\tau \in(0, T]$.

3) If a function $v$ is strictly bounded from zero on $[0, \tau]$, i. e. $\delta_{0}=\inf _{t \in[0, \tau]}|v(t)|>0$ then the ratio $q / v$ of functions in $W_{p}^{s}(0, \tau) \quad(\tau \in(0, T])$ belongs to $W_{p}^{s}(0, \tau)$ again and

$$
\|q / v\|_{W_{p}^{s}(0, \tau)} \leq c_{3}\|q\|_{W_{p}^{s}(0, \tau)}\|v\|_{W_{p}^{s}(0, \tau)},
$$

where the constant $c_{3}$ is independent of $q$ but it depends on $\delta_{0}$ and tends to $\infty$ as $\delta_{0} \rightarrow 0$.

4) Assume that $q(t) \in \tilde{W}_{p}^{s}(0, \tau) \quad(\tau \in(0, T]), \quad v(t) \in W_{p}^{s}(0, T)$, and $\Phi(t, x) \in W_{p}^{s, 2 s}(S)$. Then $q v \in \tilde{W}_{p}^{s}(0, \tau), \quad q \Phi \in \tilde{W}_{p}^{s, 2 s}\left(S^{\tau}\right)$, and

$$
\begin{gathered}
\|q v\|_{\tilde{W}_{p}^{s}(0, \tau)} \leq c\|q\|_{\tilde{W}_{p}^{s}(0, \tau)}\|v\|_{W_{p}^{s}(0, T)}, \\
\|q \Phi\|_{\tilde{W}_{p}^{s, 2 s}\left(S^{\tau}\right)} \leq c_{4}\|q\|_{\tilde{W}_{p}^{s}(0, \tau)}\|\Phi\|_{W_{p}^{s, 2 s}(S)},
\end{gathered}
$$

where the constant $c$ is independent of $\tau \in(0, T]$.

The proof can be found in [21].

We describe now the conditions on the data used below. Fix a number $s=1-1 / 2 p$ and assume that $p>3 / 2$.

The conditions on the coeficients

$$
a_{i j} \in C\left([0, T] ; W_{\infty}^{1}(G)\right) \cap L_{q}\left(G ; W_{p}^{s}(0, T)\right), \nabla_{x} a_{i j} \in L_{q}\left(G ; W_{p}^{s}(0, T)\right),
$$

where $i, j=1,2, \ldots, n, 1 / p+1 / q=1$.

$$
a_{i} \in L_{q}\left(G ; W_{p}^{s}(0, T)\right),(i=0,1, \ldots, n), \nabla_{x} a_{i} \in L_{q}\left(G ; W_{p}^{s}(0, T)\right)(i=1,2, \ldots, n) .
$$

Suppose also that there exists a constant $\delta_{0}>0$ such that

$$
\sum_{i, j=1}^{n} a_{i j} \xi_{i} \xi_{j} \geq \delta_{0}|\xi|^{2}, \forall(t, x) \in Q, \forall \xi \in \mathbb{R}^{n} .
$$

The conditions on the data of the problem

$$
\begin{gathered}
f \in L_{p}(Q), u_{0}(x) \in W_{p}^{2-2 / p}(G), \\
g \in W_{p}^{s, 2 s}(S), g(0, x)=\left.u_{0}\right|_{\Gamma}, \\
\varphi_{k} \in W_{\infty}^{2}(G), \Phi_{k} \in W_{p}^{s, 2 s}(S), \psi_{k} \in W_{p}^{s+1}(0, T),\left(f, \varphi_{k}\right) \in W_{p}^{s}(0, T), k=1,2, \ldots, m .
\end{gathered}
$$

As a consequence of Theorem 9.1 in [22, Ch. 4] (see also Theorem 10.4 in [22, Ch. 7]) we have the following theorem.

Theorem 1. Assume that $G$ is a bounded domain with boundary of the class $C^{2}$ and the conditions (9)-(13) hold. Then there exists a unique solution uto the problem (1)-(2) such that $u \in W_{p}^{1,2}(Q)$. A solution meets the estimate

$$
\|u\|_{W_{p}^{1,2}(Q)} \leq C\left(\|f\|_{L_{p}(Q)}+\left\|u_{0}\right\|_{W_{p}^{2-2 / p}(G)}+\|g\|_{W_{p}^{s, 2 s}(S)}\right) .
$$

As a consequece of Theorem 1 we have that 


\section{Математика}

Theorem 2. Assume that $G$ be a bounded domain with boundary of the class $C^{2}$ and the conditions (9)-(13) hold, where $f \equiv 0$ and $u_{0} \equiv 0$. Let $\gamma \in(0, T]$. Then there exists a unique solution $u$ to the problem (1)-(2) such that $u \in W_{p}^{1,2}\left(Q^{\gamma}\right) . \quad A$ solution meets the estimate $\|u\|_{W_{p}^{1,2}\left(Q^{\gamma}\right)} \leq c\|g\|_{\tilde{W}_{p}^{s, 2 s}\left(S^{\gamma}\right)}$, where the constant $c$ is independent of $\gamma \in(0, T]$ and $g$.

Proof. Extend the function $g$ by zero for $t<0$ and put $\tilde{g}=\left\{\begin{array}{c}g(t, x), t \in(-T+\gamma, \gamma) \\ g(2 \gamma-t, x), t \in[\gamma, T+\gamma]\end{array}\right.$. Obviously, $\tilde{g} \in W_{p}^{s, 2 s}(S)$. By Theorem 1, we can construct a solution to the problem (1)-(2), where $u_{0} \equiv 0, f \equiv 0$, and $g=\tilde{g}$ such that $u \in W_{p}^{1,2}(Q)$. Theorem 1 yields the estimate $\|u\|_{W_{p}^{1,2}\left(Q^{\gamma}\right)} \leq c\|\tilde{g}\|_{W_{p}^{s, 2 s}(S)}$. Estimate the right-hand side. Lemma 1 implies that

$$
\|\tilde{g}\|_{W_{p}^{s, 2 s}(S)} \leq\|\tilde{g}\|_{W_{p}^{s, 2 s}((-T+\gamma, T+\gamma) \times \Gamma)} \leq c\left(\|\tilde{g}\|_{\left.W_{p}^{s, 2 s}((-T+\gamma, \gamma) \times \Gamma)\right)}+\|\tilde{g}\|_{\left.W_{p}^{s, 2 s}((\gamma, T+\gamma) \times \Gamma)\right)}\right) \leq c_{1}\|g\|_{\tilde{W}_{p}^{s, 2 s}\left(S^{\gamma}\right)} .
$$

We employ the additivity of the Sobolev space with respect to the partition of a domain (see Remark 3 of Subsect. 4.4.1 in [1]) and the definition of the corresponding norm.

\section{Basic results}

In addition to the above conditions we require that

$$
|\operatorname{det} B(t)| \geq \delta_{0}>0 \quad \forall t \in[0, T]
$$

where $B(t)$ is the matrix with entries $b_{i j}=\int_{\Gamma} \frac{\partial \varphi_{i}(x)}{\partial N} \Phi_{j}(t, x) d \Gamma,\left.\varphi_{k}\right|_{\Gamma}=0(k=1, \ldots, m)$;

$$
\int_{G} u_{0}(x) \varphi_{k}(x) d x=\psi_{k}(0), \psi_{k t}(0)=\left(u_{0}, L_{0}^{*} \varphi_{k}\right)-\int_{\Gamma} u_{0}(x) \frac{\partial \varphi_{i}(x)}{\partial N} d \Gamma+\left.\left(f, \varphi_{k}\right)\right|_{t=0},
$$

where $k=1, \ldots, m$ and $L_{0}^{*}$ is a formally adjoint to the operator $L_{0}$, $L_{0} \omega=\sum_{i, j=1}^{n} \frac{\partial}{\partial x_{i}} a_{i j} \omega_{x_{j}}-\sum_{i=1}^{n} a_{i} \omega_{x_{i}}-a_{0} \omega$;

(A) the functions $\Phi_{1}(0, x), \ldots, \Phi_{m}(0, x)$ are linearly independent on $\Gamma$ and $\left.u_{0}(x)\right|_{\Gamma}$ belongs to the span of these functions.

We can note that (16) is a necessary solvability condition of the inverse problem.

Theorem 3. Assume that $G$ is a bounded domain with boundary of the class $C^{2}$ and the conditions (9)-(12), (14)-(16), and (A) hold. Then there exists a unique solution $(u, \vec{q})$ $\left(\vec{q}=\left(q_{1}, \ldots, q_{m}\right)\right)$ to the problem (1)-(3) such that $u \in W_{p}^{1,2}(Q), \vec{q} \in W_{p}^{s}(0, T)$. A solution satisfies the estimate

$$
\|u\|_{W_{p}^{1,2}(Q)}+\|\vec{q}\|_{W_{p}^{s}(0, T)} \leq C\left(\|f\|_{L_{p}(Q)}+\left\|u_{0}\right\|_{W_{p}^{2-2 / p}(G)}+\sum_{i=1}^{m}\left(\left\|\psi_{i}\right\|_{W_{p}^{1+s}(0, T)}+\left\|\left(f, \varphi_{i}\right)\right\|_{W_{p}^{s}(0, T)}\right)\right) .
$$

Proof. Let $u \in W_{p}^{1,2}(Q)$ be a solution to the problem (1)-(3), where $g=\sum_{i=1}^{m} q_{i} \Phi_{i}$. The conditions (15) and (A) imply that there exists a unique collection of constants $q_{i}(0)$ such that $\left.u_{0}\right|_{\Gamma}=\sum_{i=1}^{m} q_{i}(0) \Phi_{i}(0, x)$. Put $\sum_{i=1}^{m} q_{i}(0) \Phi_{i}(t, x)=g_{0}(t, x)$ and denote by $v \in W_{p}^{1,2}(Q)$ a solution to the problem (see Theorem 1)

$$
L v=f,\left.v\right|_{S}=g_{0}(t, x),\left.v\right|_{t=0}=u_{0}(x) .
$$

Let $\vec{q} \in W_{p}^{s}(0, T)$. In view of our conditions $\Phi_{j} \in W_{p}^{s, 2 s}(S)$. Lemma 1 yields $q_{i}(t) \Phi_{i}(t, x) \in W_{p}^{s, 2 s}(S)$ and thus $g \in W_{p}^{s, 2 s}(S)$. Make the change of variables $u=v+\omega$. The function $\omega \in W_{p}^{1,2}(Q)$ is a solution to the problem

$$
L \omega=0,\left.B \omega\right|_{S}=g-g_{0}=\tilde{g},\left.\omega\right|_{t=0}=0 .
$$


The condition (3) transforms into the form

$$
\int_{G} \omega \varphi_{k}(x) d x=\psi_{k}-\int_{G} v(t, x) \varphi_{k}(x) d x=\tilde{\psi}_{k}, k=1,2, \ldots, m .
$$

By (16), $\tilde{\psi}_{k}(0)=0$ and we have at least that $\tilde{\psi}_{k}(t) \in W_{p}^{1}(0, T)$. Below we demonstrate that $\tilde{\psi}_{k}(t) \in W_{p}^{1+s}(0, T)$ and $\tilde{\psi}_{k}^{\prime}(0)=0$. Multiply the equation in (18) by $\varphi_{k}(x)$ and integrate the result over $G$. We obtain that $\left(\omega_{t}, \varphi_{k}\right)=\left(L_{0} \omega, \varphi_{k}\right)$. Using (18), (19), and integrating by parts, we infer

$$
\tilde{\psi}_{k}^{\prime}(t)=\left(\omega, L_{0}^{*} \varphi_{k}\right)-\sum_{i=1}^{m} \tilde{q}_{i}(t) \int_{\Gamma} \Phi_{i} \frac{\partial \varphi_{k}(x)}{\partial N} d \Gamma, k=1, \ldots, m, \tilde{q}_{i}(t)=q_{i}(t)-q_{i}(0) .
$$

The last inequality can be written in either of the forms

$$
\sum_{i=1}^{m} \tilde{q}_{i}(t) b_{k i}=-\tilde{\psi}_{k}^{\prime}(t)+\left(\omega, L_{0}^{*} \varphi_{k}\right)
$$

or

$$
B \vec{q}_{a}=\vec{F}+R\left(\vec{q}_{a}\right), \vec{F}=\left(F_{1}, \ldots, F_{m}\right)^{T}, F_{k}=-\tilde{\psi}_{k}^{\prime}(t),\left(R\left(\vec{q}_{a}\right)\right)_{k}=\left(\omega, L_{0}^{*} \varphi_{k}\right),
$$

where $\vec{q}_{a}=\left(\tilde{q}_{1}, \ldots, \tilde{q}_{m}\right)^{T}$. The function $\omega$ in (21) is a solution to the direct problem (18). The entries of $B$ possess the property $b_{i j} \in W_{p}^{s}(0, T)$ and even more we have the inequality

$$
\left\|b_{i j}\right\|_{W_{p}^{s}(0, T)} \leq\left\|\Phi_{j}\right\|_{L_{p}\left(\Gamma ; W_{p}^{s}(0, T)\right)}\left\|\varphi_{i}\right\|_{C^{1}(\bar{G})} .
$$

As was noticed in the proof of Lemma 1, the embedding theorems state that $W_{p}^{s}(0, T) \subset C([0, T])$. Hence, we can assume that $b_{i j} \in C([0, T])$. In view of (15), we can write

$$
\vec{q}_{a}=B^{-1} \vec{F}+R_{0}\left(\vec{q}_{a}\right), R_{0}\left(\vec{q}_{a}\right)=B^{-1} R\left(\vec{q}_{a}\right) .
$$

We can determine the vector $\vec{q}_{a}$ from this equation. Indeed, consider the segment $[0, \delta] \subset[0, T]$ and estimate the quantity $\left\|R_{0}\left(\vec{q}_{a}\right)\right\|_{\tilde{W}_{p}^{s}(0, \delta)}$. The second and third statements of Lemma 1 and the conditions on the coeffcients and the functions $\varphi_{k}$ imply that the entries of the inverse matrix $B^{-1}$ also belong to the class $W_{p}^{s}(0, T)$. In this case the estimate (7) and Lemma 1 yield

$$
\left\|R_{0}\left(\vec{q}_{a}\right)\right\|_{\tilde{W}_{p}^{s}(0, \delta)} \leq c \sum_{k=1}^{m}\left\|\left(\omega, L_{0}^{*} \varphi_{k}\right)\right\|_{\tilde{W}_{p}^{s}(0, \delta)} .
$$

Estimate the norm of the expression $\left(\omega, L_{0}^{*} \varphi_{k}\right)$. The Minkowski and Holder inequalities and Lemma 1 ensure that

$$
\left\|\left(\omega, L_{0}^{*} \varphi_{k}\right)\right\|_{L_{p}(0, \delta)} \leq\|\omega\|_{L_{p}\left(G ; \tilde{W}_{p}^{s}(0, \delta)\right)}\left\|L_{0}^{*} \varphi_{k}\right\|_{L_{q}\left(G ; W_{p}^{s}(0, T)\right)} .
$$

In view of our conditions on the coefficients, the last factor is estimated by some constant independent of $\delta$. Estimate the first factor. We have

$$
\int_{G}\|\omega\|_{\tilde{W}_{p}^{s}(0, \delta)}^{p} d x=\int_{G} \int_{0}^{\delta} \frac{|\omega|^{p}}{t^{s p}} d t d x+\int_{G} \int_{0}^{\delta} \int_{0}^{\delta} \frac{\left|\omega\left(t_{1}, x\right)-\omega\left(t_{2}, x\right)\right|^{p}}{\left|t_{1}-t_{2}\right|^{1+s p}} d t_{1} d t_{2} d x
$$

The Newton-Leibnitz formula validates the inequality

$$
\left\|\frac{1}{t^{s}} \omega\right\|_{L_{p}\left(Q^{\delta}\right)} \leq c_{1} \delta^{1 / 2}\left\|\omega_{t}\right\|_{L_{p}\left(Q^{\delta}\right)}
$$

Estimate the second summand on the right-hand side of (25). To this end, we first make the change of variables $t_{1}=\tau_{1} \delta, \quad t_{2}=\tau_{2} \delta$ and next use the inequality $\|\tilde{\omega}(x, \tau)\|_{W_{p}^{s}(0,1)} \leq c\left\|\tilde{\omega}_{\tau}\right\|_{L_{p}(0,1)}$ $(\tilde{\omega}(x, \tau))=\omega(x, \delta \tau))$ followed by the inverse change of variables. As a result, we arrive at the inequality

$$
\iint_{G 00}^{\delta \delta} \frac{\left|\omega\left(t_{1}, x\right)-\omega\left(t_{2}, x\right)\right|^{p}}{\left|t_{1}-t_{2}\right|^{1+s p}} d t_{1} d t_{2} d x \leq c_{1} \int_{G 0}^{\delta} \int_{0}\left|\omega_{t}(t, x)\right| d t d x \delta^{1 / 2} .
$$




\section{Математика}

Thus, from (25)-(27) it follows that

$$
\int_{G}\|\omega\|_{\tilde{W}_{p}^{s}(0, \delta)}^{p} d x \leq c_{2} \delta^{1 / 2}\left\|\omega_{t}\right\|_{L_{p}\left(Q^{\delta}\right)} \leq c_{2} \delta^{1 / 2}\|\omega\|_{W_{p}^{1,2}\left(Q^{\delta}\right)} .
$$

Therefore, taking (23) and Theorem 2 into account, we obtain the estimate

$$
\left\|R_{0}\left(\vec{q}_{a}\right)\right\|_{\tilde{W}_{p}^{s}(0, \delta)} \leq c_{3} c \delta^{1 / 2}\|\omega\|_{W_{p}^{1,2}\left(Q^{\delta}\right)} \leq c_{4} \delta^{1 / 2}\|\tilde{g}\|_{W_{p}^{s, 2 s}\left(Q^{\delta}\right)} .
$$

Lemma 1 implies the inequality

$$
\left\|R_{0}\left(\vec{q}_{a}\right)\right\|_{\tilde{W}_{p}^{s}(0, \delta)} \leq c_{5} \delta^{1 / 2}\left\|\vec{q}_{a}\right\|_{\tilde{W}_{p}^{s}(0, \delta)},
$$

where the constant $c_{5}$ is independent of $\delta$ and $\vec{q}_{a}$. Fix $\delta>0$ such that $\delta^{1 / 2} c_{5}<1$. In this case the operator $R_{0}$ is a contraction and thereby the equaiton (22) is uniquely solvable in the space $W_{p}^{s}(0, \delta)$, of course under the condition that $\tilde{\psi}_{k}{ }^{\prime} \in \tilde{W}_{p}^{s}(0, T)$. We have that $\psi_{k}{ }^{\prime} \in W_{p}^{s}(0, T)$. Show that $\psi_{0 k}=\int_{G} v(t, x) \varphi_{k}(x) d x \in W_{p}^{1+s}(0, T)$ and $\psi_{0 k}^{\prime}(0)=\psi_{k}^{\prime}(0)$, i. e., $\tilde{\psi}_{k t} \in \tilde{W}_{p}^{s}(0, T)$. Multiply the equation in (17) by $\varphi_{k}$ and integrate the result over $G$. We infer

$$
\psi_{0 k}{ }^{\prime}(t)=\left(\omega, L_{0}^{*} \varphi_{k}\right)-\sum_{i=1}^{m} q_{i}(0) \int_{\Gamma} \Phi_{i} \frac{\partial \varphi_{k}(x)}{\partial N} d \Gamma+\left(f, \varphi_{k}\right),, k=1, \ldots, m .
$$

In view of the condition (14) the right-hand side in this equality belongs to $W_{p}^{s}(0, T)$ and the relations (16) and (31) for $t=0$ yield $\psi_{0 k}^{\prime}(0)=\psi_{k}^{\prime}(0)$. Thus, $\tilde{\psi}_{k} \in \tilde{W}_{p}^{s}(0, T)$ for all $k$ and thus the equation (22) is uniquely solvable on the segment $[0, \delta]$. Find a solution $\omega \in W_{p}^{1,2}\left(Q^{\delta}\right)$ to the problem (18). Prove (19). Multiply the equation in (18) by $\varphi_{k}$ and integrate the results over $G$. Using (17), (18), and integrating by parts, we obtain the equality

$$
\left(\omega_{t}, \varphi_{k}\right)=\left(\omega, L_{0}^{*} \varphi_{k}\right)-\sum_{i=1}^{m} \tilde{q}_{i}(t) \int_{\Gamma} \Phi_{i} \frac{\partial \varphi_{k}(x)}{\partial N} d \Gamma, k=1, \ldots, m .
$$

The vector-function $\vec{q}_{a}$ satisfies the system (20), subtracting its $k$-th equation from this equality and cancelling, we arrive at the equality $\int_{G} \omega_{t} \varphi_{k} d x=\tilde{\psi}_{k}{ }^{\prime}, k=1, \ldots, m$, whose integration with respect to $t$ and the intial condition validate $(19)$ on $[0, \delta]$.

We now demonstrate that this solution is extendible to the whole segment $[0, T]$. We have defined the vector-function $\vec{q}_{a}$ only on $[0, \delta]$. Extend $\vec{q}_{a}$ by zero for $t<0$ and denote $\vec{q}_{b}=\left\{\begin{array}{c}\vec{q}_{a}(t), t \in(0, \delta) \\ \vec{q}_{a}(2 \delta-t), t \in[\delta, T]\end{array}\right.$. The coordinates of $\vec{q}_{b}$ are denoted by $q_{1}^{b}, \ldots, q_{m}^{b}$. This vector-function belongs to $W_{p}^{s, 2 s}(S)$. Make the change $\vec{q}^{1}=\vec{q}_{a}-\vec{q}_{b}$. The vector-function with the coordinates $q_{i}^{1}$ is a solution to the system

$$
\sum_{i=1}^{m} q_{i}^{1}(t) b_{k i}=\tilde{\psi}_{k}^{\prime}(t)+\left(\omega, L_{0}^{*} \varphi_{k}\right)-\sum_{i=1}^{m} q_{i}^{b}(t) b_{k i} .
$$

By definition of $\vec{q}_{b}$, the right-hand side in this equality and the vector $\vec{q}^{1}$ vanish on $[0, \delta]$. Let $\omega_{0}$ - be a solution to the problem

$$
L \omega_{0}=0,\left.B \omega_{0}\right|_{S}=\sum_{i=1}^{m} q_{i}^{b} \Phi_{i},\left.\omega_{0}\right|_{t=0}=0 .
$$

In this case the function $\omega_{1}=\omega-\omega_{0}$ is a solution to the problem

$$
L \omega_{1}=0,\left.B \omega_{1}\right|_{S}=\sum_{i=1}^{m} q_{i}^{1} \Phi_{i},\left.\omega_{1}\right|_{t=0}=0 .
$$


By Theorem $1, \omega_{1}=0$ for $t \in[0, \delta]$. Thus, the problem of extension of $\vec{q}_{a}$ is reduced to solving the system

$$
\sum_{i=1}^{m} q_{i}^{1}(t) b_{k i}=\psi_{1 k}^{\prime}(t)+\left(\omega_{1}, L_{0}^{*} \varphi_{k}\right)
$$

where $\psi_{1 k}{ }^{\prime}=\tilde{\psi}_{k}{ }^{\prime}(t)+\left(\omega_{0}, L_{0}^{*} \varphi_{k}\right)-\sum_{i=1}^{m} q_{i}^{b}(t) b_{k i}$, and $\omega_{1}$ is a solution to the problem (34). A solution to the system vanishes for $t \leq \delta$. We obtain the same system with zero Cauchy data at the point $t=\delta$ and a new right-hand side $\vec{F}$. Next, we repeat the same arguments and estimates on the segment $[\delta, 2 \delta]$. Without loss of generality, we can assume that the constants arising in estimating the norm of the operator $R_{0}$ are the same. Thus, the system (35) is solvable on $[\delta, 2 \delta]$. Repeating the arguments on $[2 \delta, 3 \delta]$ and so on, we can construct a solution on the whole segment $[0, T]$. The estimate in the claim of the theorem has been actually proven in the proof.

Remark. At first sight, the well-posedness conditions (15) look rather strange and possibly arising in the method of the proof. However, employing other methods leads actually to the same condtitions. It is possible that they are essential.

\section{Acknowledgement}

The authors were supported by the grant on development of scientific schools with participation of young scientists of the Yugra State University.

\section{References}

1. Triebel H. Interpolation Theory, Function Spaces, Differential Operators, North-Holland Mathematical Library, Vol. 18, Amsterdam, North-Holland Publishing, 1978, 528 p.

2. Alifanov O.M., Artyukhin E.A., Nenarokomov A.V. Obratnye zadachi v issledovanii slozhnogo teploobmena. Moscow, Yanus-K Publ., 2009, 299 p. (in Russ.).

3. Ozisik M.N., Orlando H.A.B. Inverse heat transfer. New-York, Taylor \& Francis, 2000, 352 p.

4. Kostin A.B., Prilepko A.I. On some problems of recovering a boundary condition for a parabolic equation, I. Differ. Equations, 1996, Vol. 32, no. 1, pp. 113-122. (in Russ.).

5. Borukhov V.T., Korzyuk V.I. Primenenie neklassicheskikh kraevykh zadach dlya vosstanovleniya granichnykh rezhimov protsessov perenosa (Application of nonclassical boundary value problems for recovering boundary regimes of transfer processes). Vestnik Belorusskogo universiteta (Bulletin of Belarussian University), 1998, Ser. 1, no. 3, pp. 54-57. (in Russ.).

6. Tryanin A.P. Determination of heat-transfer coefficients at the inlet into a porous body and inside it by solving the inverse problem. Journal of engineering physics, 1987, Vol. 52, Issue 3, pp. 346-351. DOI: $10.1007 / \mathrm{BF} 00872521$

7. Borukhov V.T., Vabishchevich P.N., Korzyuk V.I. Reduction of a class of inverse heatconduction problems to direct initial/boundary-value problems. Journal of Engineering Physics and Thermophysics, 2000, Vol. 73, Issue 4, pp. 730-734. DOI: 10.1007/s10891-000-0082-9

8. Korotkii A.I., Kovtunov D. A. Reconstruction of boundary regimes in an inverse heat convection problem for an incompressible fluid. Tr. IMM DVO AN, 2006, Vol. 12, no. 2, pp. 88-97. (in Russ.).

9. Abylkairov U.U. Obratnaya zadacha integral'nogo nablyudeniya dlya obshchego parabolicheskogo uravneniya. Matematicheskiy zhurnal, 2003, Vol. 3, no. 4(10), pp. 5-12. (in Russ.).

10. Abylkairov U.U., Abiev A.A., Aitzhanov S.E. Obratnaya zadacha dlya sistemy teplovoy konvektsii (Inverse problem for the system of thermal convection). Proc. International Youth Scientific School-Conference "Theory and numerical methods for solving inverse and ill-posed problems", Novosibirsk, IM SB RAS Publ., 2009, pp. 10-11. (in Russ.).

11. Kozhanov A.I. Linear inverse problems for some lasses of nonstationary equations. Proc. VI International scientific school-conference for young scientists "Theory and numerical methods for solving inverse and ill-posed problem", 2015, pp. 264-275. (in Russ.). DOI 10.17377/semi.2015.12.089

12. Iskenderov A.D., Akhundov A.Ya. Inverse problem for a linear system of parabolic equations. Doklady Mathematics, 2009, Vol. 79, no. 1, pp. 73-75. DOI: 10.1134/S1064562409010219 


\title{
Математика
}

13. Ismailov M.I., Kanca F. Inverse problem of finding the time-dependent coefficient of heat equation from integral overdetermination condition data. Inverse Problems in Science and Engineering, 2012, Vol. 20, no. 24, pp. 463-476. DOI: 10.1080/17415977.2011.629093

14. Li J., Xu Y. An inverse coefficient problem with nonlinear parabolic equation. J. Appl. Math. Comput., 2010, Vol. 34, pp. 195-206. DOI: 10.1007/s12190-009-0316-8

15. Kerimov N.B., Ismailov M.I. An inverse coefficient problem for the heat equation in the case of nonlocal boundary conditions. J. of Mathematical Analysis and Applications, 2012, Vol. 396, Issue 2, pp. 546-554. DOI:10.1016/j.jmaa.2012.06.046

16. Kozhanov A.I. Parabolic equations with unknown time-dependent coefficients. Comput. Math. and Math. Phys., 2017, Vol. 57, no. 6, pp. 956-966. DOI: 10.1134/S0965542517060082.

17. Pyatkov S.G., Safonov E.I. Determination of the Source Function in the Mathematical Models of Convection-Diffusion. Mathematical notes of NEFU, 2014, Vol. 21, no. 2, pp. 117-130. (in Russ.).

18. Kriksin Yu.A., Plushchev S.N., Samarskaya E.A., Tishkin V.F. The inverse problem of source reconstruction for convective diffusion equation. Matem. Mod., 1995, Vol. 7, no. 11, pp. 95-108. (in Russ.).

19. Prilepko A.I., Orlovsky D.G., Vasin I.A. Methods for solving inverse problems in Mathematical Physics. New-York, Marcel Dekker, Inc., 1999, 744 p. DOI: 10.1201/9781482292985

20. Ivanchov M. Inverse problems for equations of parabolic type. Mathematical Studies Monograph Series 10, Lviv, VNTL Publishers, 2003, 238 p.

21. Verzhbitskii M.A., Pyatkov S.G. On Some Inverse Problems of Determining Boundary Regimes. Mathematical notes of NEFU, 2016, Vol. 23, no. 2, pp. 3-16. (in Russ.).

22. Ladyženskaja O.A., Solonnikov V.A., Uralceva N.N. Linear and quasilinear equations of parabolic type. Translations of Mathematical Monographs, Vol. 23 American Mathematical Society, Providence, R.I., 1968, 648 p. DOI: 10.1090/mmono/023

23. Denk R., Hieber M., Prüss J. Optimal $L_{p}-L_{q}$-estimates for parabolic boundary value problems with inhomogeneous data. Math. Z., 2007, Vol. 257, no. 1, pp. 193-224. DOI: 10.1007/s00209-007$0120-9$

Received February 6, 2018

Bulletin of the South Ural State University Series "Mathematics. Mechanics. Physics" 2018, vol. 10, no. 2, pp. 37-46

удк 517.956

DOI: $10.14529 / \mathrm{mmph} 180204$

\section{ОБРАТНЫЕ ЗАДАЧИ ОБ ОПРЕДЕЛЕНИИ ГРАНИЧНЫХ ДАННЫХ С ИНТЕГРАЛЬНЫМИ УСЛОВИЯМИ ПЕРЕОПРЕДЕЛЕНИЯ ${ }^{1}$}

\author{
С.Г. Пятков, М.А. Вержбицкий \\ Югорский государственный университет, г. Ханты-Мансийск, Российская Федерация \\ E-mail: s_pyakov@ugrasu.ru
}

Рассматривается обратная задача об определении вместе с решением начально-краевой задачи для параболического уравнения второго порядка неизвестных функций, входящих в граничное условие Дирихле. Задачи такого вида об определении граничных данных возникают в самых различных задачах математической физики: управление процессами теплообмена и проектирование тепловой защиты, диагностика и идентификация теплопередачи в сверхзвуковых гетерогенных потоках, идентификация и моделирование теплопереноса в теплозащитных материалах и покрытиях, моделирование свойств и тепловых режимов многоразовой тепловой защиты аэрокосмических аппаратов, исследование композиционных материалов и т. п. В качестве условий переопределения берутся интегралы от решения по пространственной области

\footnotetext{
${ }^{1}$ Публикация подготовлена в результате проведения научного исследования за счет средств гранта на развитие научных школ с участием молодых ученых федерального государственного бюджетного образовательного учреждения высшего образования «Югорский государственный университет»
} 
с весами. Проблема сводится к операторному уравнению типа Вольтерра. Мы устанавливаем теорему существования и единственности решений этой обратной задачи в пространствах Соболева. Решение является регулярным, т.е. все обобщенные производные, входящие в уравнение существуют и суммируемы с некоторой степенью. Доказательство основано на теореме о неподвижной точке и последовательном доказательстве разрешимости на малых промежутках времени. Приведена также оценка устойчивости решений. Полученные условия разрешимости близки к необходимым условиям.

Ключевые слова: обратная задача; параболическое уравнение; краевые и начальные условия; пространство Соболева; теорема существования и единственности; разрешимость.

\section{Литература}

1. Трибель, Х. Теория интерполяции. Функциональные пространства. Дифференциальные операторы / Х. Трибель. - М.: Мир, 1980. - 664 с.

2. Алифанов, О.М. Обратные задачи в исследовании сложного теплообмена / О.М. Алифанов, Е.А. Артюхин, А.В. Ненарокомов. - Москва: Янус-К, 2009. - 299 с.

3. Ozisik, M.N. Inverse heat transfer / M.N. Ozisik, H.A.B. Orlando. - New-York: Taylor \& Francis, 2000. -352 p.

4. Костин, А.Б. О некоторых задачах восстановления граничного условия для параболического уравнения. I / А.Б. Костин, А.И. Прилепко // Дифференц. уравнения. - 1996. - Т. 32, № 1. C. $107-116$.

5. Борухов, В.Т. Применение неклассических краевых задач для восстановления граничных режимов процессов переноса / В.Т. Борухов, В.И. Корзюк // Вестник Белорусского университета. - 1998. - Cep. 1, № 3. - С. 54-57.

6. Трянин, А.П. Определение коэффициентов теплообмена на входе в пористое тело и внутри него из решения обратной задачи / А.П. Трянин // Инженерно-физический журнал. - 1987. T. 52, № 3. - С. 469-475.

7. Борухов, В.Т. Сведение одного класса обратных задач теплопроводности к прямым начально-краевым задачам / В.Т. Борухов, П.Н. Вабищевич, В.И. Корзюк // Инженерно-физический журнал. - 2000. - Т. 73, № 4. - С. 742-747.

8. Короткий, А.И. Реконструкция граничных режимов в обратной задаче тепловой конвекции несжимаемой жидкости / А.И. Короткий, Д.А. Ковтунов // Тр. ИММ ДВО АН. - 2006. - Т. 12, № 2. - С. 88-97.

9. Абылкаиров, У.У. Обратная задача интегрального наблюдения для общего параболического уравнения / У.У. Абылкаиров // Математический журнал. - 2003. - Т. 3, № 4(10). - С. 5-12.

10. Абылкаиров, У.У. Обратная задача для системы тепловой конвекции / У.У. Абылкаиров, А.А. Абиев, С.Е. Айтжанов // Тезисы докладов Молодежной международной научной школыконференции «Теория и численные методы решения обратных и некорректных задач». - Новосибирск, ИМ СО РАН, 2009. - С. 10-11.

11. Кожанов, А.И. Линейные обратные задачи для некоторых классов нелинейных нестационарных уравнений / А.И. Кожанов // Сибирские электронные математические известия. - 2015. T. 12. - C. 264-275.

12. Iskenderov, A.D. Inverse problem for a linear system of parabolic equations / A.D. Iskenderov, A.Ya. Akhundov // Doklady Mathematics. - 2009. - Vol. 79, no. 1. - P. 73-75.

13. Ismailov, M.I. Inverse problem of finding the time-dependent coefficient of heat equation from integral overdetermination condition data / M.I. Ismailov, F. Kanca // Inverse Problems in Science and Engineering. - 2012. - Vol. 20, № 24. - P. 463-476.

14. Li, J. An inverse coefficient problem with nonlinear parabolic equation / J. Li, Y. Xu // J. Appl. Math. Comput. - 2010. - Vol. 34. - P. 195-206.

15. Kerimov, N.B. An inverse coefficient problem for the heat equation in the case of nonlocal boundary conditions / N.B. Kerimov, M.I. Ismailov // J. of Mathematical Analysis and Applications. 2012. - Vol. 396. - Issue 2. - P. 546-554.

16. Kozhanov, A.I. Parabolic equations with unknown time-dependent coefficients / A.I. Kozhanov // Comput. Math. and Math. Phys. - 2017. - Vol. 57, № 6. - P. 956-966. 


\section{Математика}

17. Пятков С.Г. Об определении функции источника в математических моделях конвекциидиффузии / С.Г. Пятков, А.Е. Сафонов // Математические заметки СВФУ. - 2014. - Т. 21, № 2. C. $117-130$.

18. Обратная задача восстановления плотности источника для уравнения конвекциидиффузии / Ю.А. Криксин, С.Н. Плющев, Е.А. Самарская, В.Ф. Тишкин // Математическое моделирование. - 1995. - Т. 7, № 11. - С. 95-108.

19. Prilepko, A.I. Methods for solving inverse problems in Mathematical Physics / A.I. Prilepko, D.G. Orlovsky, I.A. Vasin. - New-York: Marcel Dekker, Inc. 1999. - 744 p.

20. Ivanchov, M. Inverse problems for equations of parabolic type / M. Ivancho // Mathematical Studies Monograph Series 10. - Lviv: VNTL Publishers, 2003. - 238 p.

21. Вержбицкий, М.А. О некоторых обратных задачах об определении граничных режимов / М.А. Вержбицкий, С.Г. Пятков // Матем. Заметки СВФУ. - 2016. - Т. 23, № 2. - С. 3-16.

22. Ladyženskaja, O.A. Linear and quasilinear equations of parabolic type / O.A. Ladyženskaja, V.A. Solonnikov, N.N. Uralceva // Translations of Mathematical Monographs. - Vol. 23. - American Mathematical Society, Providence, R.I., 1968. - 648 p.

23. Denk, R. Optimal $L_{\mathrm{p}}-L_{\mathrm{q}}$-estimates for parabolic boundary value problems with inhomogeneous data / R. Denk, M. Hieber, J. Prüss // Math. Z. - 2007. - Vol. 257, no. 1. - P. 193-224.

Поступила в редакцию 6 февраля 2018 г. 